\title{
I.S.Mu.L.T. first-time patellar dislocation guidelines
}

\author{
Mario Vetrano 1 \\ Francesco Oliva ${ }^{2}$ \\ Salvatore Bisicchia ${ }^{4}$ \\ Michela Bossa ${ }^{5}$ \\ Angelo De Carli6 \\ Luigi Di Lorenzo7,8 \\ Davide Erroi ${ }^{1}$ \\ Alfonso Forte 8 \\ Calogero Foti ${ }^{5}$ \\ Antonio Frizziero ${ }^{9}$ \\ Giuseppe Gasparre ${ }^{9}$ \\ Alessio Giai Via ${ }^{2}$ \\ Bernardo Innocenti ${ }^{10}$ \\ Umile Giuseppe Longo ${ }^{3}$ \\ Asmaa Mahmoud 5 \\ Stefano Masiero ${ }^{9}$ \\ Daniele Mazza ${ }^{6}$ \\ Simone Natali ${ }^{2}$ \\ Christian Notarangelo ${ }^{9}$ \\ Leonardo Osti ${ }^{11}$ \\ Johnny Padulo ${ }^{12}$ \\ Leonardo Pellicciari ${ }^{5}$ \\ Fabrizio Perroni ${ }^{13}$ \\ Eleonora Piccirilli2 ${ }^{2}$ \\ Carlo Ramponi ${ }^{14}$ \\ Giuseppe Salvatore ${ }^{3}$ \\ Alfredo Schiavone Panni ${ }^{15}$ \\ Tania Suarez ${ }^{1}$ \\ Umberto Tarantino ${ }^{2}$ \\ Filippo Vittadini ${ }^{9}$ \\ Maria Chiara Vulpiani ${ }^{1}$ \\ Andrea Ferretti ${ }^{6}$ \\ Nicola Maffulli ${ }^{16}$
}

1 Physical Medicine and Rehabilitation Unit, Sant'Andrea Hospital, "Sapienza" University of Rome, Rome, Italy

2 Department of Orthopaedics and Traumatology, University of Rome "Tor Vergata", Rome, Italy

3 Department of Orthopedic and Traumatology, University Campus Bio-Medico of Rome, Rome, Italy

4 Department of Orthopaedic Surgery, San Pietro Fatebenefratelli Hospital, Rome, Italy

5 Department of Physical Medicine and Rehabilitation, University of Rome "Tor Vergata", Rome, Italy

6 Orthopaedic Department and "Kirk Kilgour" Sports Injury Center, Sant'Andrea Hospital, "Sapienza" University of Rome, Rome, Italy

7 Rehabilitation Unit, Neuroscience Department, "RUMMO" Hospital, Benevento, Italy
8 Biomedical Research Centre, Gruppo Forte, Salerno, Italy

9 Department of Physical and Rehabilitation Medicine, University of Padova, Padova, Italy

10 BEAMS Department (Bio Electro and Mechanical Systems), École Polytechnique de Bruxelles, Université Libre de Bruxelles, Brussels, Belgium

11 Unit of Arthroscopy and Sports Trauma Surgery, Hesperia Hospital, Modena, Italy

12 University eCampus, Novedrate, Italy; Tunisian Research Laboratory "Sports Performance Optimization", National Center of Medicine and Science in Sport, Tunis, Tunisia; Faculty of Kinesiology, University of Split, Split, Croatia

13 School of Exercise and Sport Sciences (SUISM), Department of Medical Sciences, University of Turin, Turin, Italy

14 Sport Physical Therapist, Kinè Physiotherapic Center, Conegliano, Italy

15 Multidisciplinary Department of Medical-Surgical and Dental Specialty, University of Campania Luigi Vanvitelli, Naples, Italy

16 Department of Musculoskeletal Disorders, Faculty of Medicine and Surgery, University of Salerno, Salerno, Italy; Centre for Sports and Exercise Medicine, Barts and The London School of Medicine and Dentistry, Queen Mary University of London, London, UK

Corresponding author:

Francesco Oliva

Department of Orthopaedics and Traumatology

University of Rome "Tor Vergata"

Viale Oxford 81

00133 Rome, Italy

E-mail: olivafrancesco@hotmail.com

\section{Summary}

Primary traumatic patellar dislocation is common, particularly in young active individuals. A consensus on its management is still lacking. The present work provides easily accessible guidelines to be considered as recommendations for a good clinical practice developed through a process of systematic review of the literature and expert opinion, to improve the quality of care and rationalize the use of resources.

Level of evidence: la. 
KEY WORDS: first-time patellar dislocation, patellar instability, surgery, patella, rehabilitation, guidelines.

\section{Introduction}

Acute patellar dislocation is a common knee injury which typically occurs in young and physically active individuals, and is associated with a high rate of recurrent patellar instability, instability symptoms and eventually patellofemoral osteoarthritis. A variable amount of anatomic abnormalities may be involved in patients with primary patellar dislocation. Usually, conservative treatment is the initial management. Surgical intervention is required for patients who are at a high risk of redislocation or when conservative management has failed. However, there remains little consensus about the optimal operative or nonoperative method of managing these patients.

\section{Approach to guidelines}

These recommendations developed through a process of systematic review of the literature and expert opinion, to be used to improve the quality of care and rationalize the use of resources. Clinical decisions on individual patients require the application of the recommendations, based on the best scientific evidence and clinical experience of the physician.

\section{Methodology}

The Authors were divided into four groups:

- A Coordinator conceived and organized the work and the groups, and selected the most important questions on the topic at hand

- A Control Group controlled the development of the work and discussed the recommendations

- The Group of the experts individually received a question and developed the Answers according to the rules of EBM, when it was possible

- The Group of Preparation and Evaluation of Literature drew up the text and assisted the group of experts in evaluating the literature.

\section{Methods and criteria study selection}

For research were consulted the following databases:

- PubMed

- Embase

- Google Scholar

- Cochrane Library.

Randomized controlled trials (RCTs); Systematic reviews; to follow if missing the first two, the other levels of evidence. The literature is updated at November, 2015.

Level of Criteria for analysis and inclusion Evidence

Meta-analyses and systematic reviews of randomized controlled trials (RCTs) of

high quality, or RCTs with minimum or low risk of bias. Systematic reviews of high quality relative to cohort studies or casecontrol

II Cohort studies or randomized case-control high quality, with minimal risk of confounding or bias and with high or discrete probability of causation.

III Case-control studies and retrospective comparison of well-conducted with reasonable probability of causation

IV Non-analytic studies as case series or individual cases

\section{Level of Criteria for analysis}

Recom-

mendation

A

B

C

D
Supported by at least two studies of level Ib or from a review level la ("it was shown")

B Supported by at least two independent studies of level II or extrapolations from studies of level I ("it is possible")

Not supported by adequate studies of level I or II ("indications")

Indications of experts ("there is no evidence")

\section{Epidemiology}

Acute dislocation of the patella represents about $3 \%$ of all knee injuries and is the second most common cause of post traumatic haemarthrosis. It can result from direct or indirect trauma in a knee without apparent patellar instability or, more often, with underlying predisposing factors to instability. A distinction must be made between dislocation and subluxation. Irreducible dislocation of the patella is rare. Usually, the first episode of acute patellar dislocation occurs in patients younger than 20 years in about $70 \%$ of cases, with an incidence of about 29 cases per 100,000 population. Some Authors point out that the incidence may reach 69 cases per 100,000 inhabitants in the military population subjected to physical efficiency tests during their military service. The incidence tends to gradually decrease with age; it is reported a percentage of about $20 \%$ in the third decade, of $5 \%$ in the fourth, and of $3.5 \%$ in the fifth and sixth decades of life. Half of the patients involved are women, and $20 \%$ of these women will experience subsequent episodes of dislocation. The first dislocation of the patella typically results from sports injuries and this is the reason why it occurs in people younger than 25 years or in "high demanders" in 2/3 of cases. It should be noted the impact of dancing in the pathogenesis of this disease ( $9 \%$ of cases). However, it may occur during the usual activities of daily living in about $21 \%$ of cases.

In an MRI study performed immediately after a first episode of acute patellar dislocation, Paakkala et al. showed a lesion of the medial patellofemoral ligament (MPFL) in $83 \%$ of cases, $70 \%$ on the patellar side of 
the ligament, $57 \%$ on its femoral side. In addition to the capsuloligamentous injuries, osteochondral lesions of the patella or of the femoral condyles may occur in a percentage that varies according to the Authors and to the methods used to highlight them. Redislocation of the patella seems more common in adolescent patients, and this event can occur both in patients treated conservatively and in those undergoing surgery, with different percentages depending on the patient cohorts ${ }^{1-7}$.

Key points:

- Acute patellar dislocation is common

- A distinction must be made between dislocation and subluxation

- In about $70 \%$ of cases, it involves subjects younger than 20

- It usually follows a trauma sustained during physical or sports activity, especially in subjects with underlying predisposing factors of patellar instability

- In patellar dislocation, capsuloligamentous injuries and/or osteochondral lesions of the patella or of the femoral condyles may occur.

\section{Biomechanics of the patellofemoral joint}

The relative motion between the distal femur and the patella, and accordingly the patellar stability, depends on four main factors: the joint geometry, the action of the muscles that act on the patella, the alignment of the lower limb, and the passive constraint exerted by the surrounding soft tissues. Physiologically, in the frontal plane, contraction of the quadriceps determines a lateral force acting on the patella, consequent to the angle, named $Q$ angle, between the line of action of the quadriceps and the patellar tendon. An increased $Q$ angle leads to an increase of this lateral force and, therefore, a greater risk of dislocation. The main antagonist to lateral patellar displacement is the femoral trochlear groove, especially the depth and pitch of the lateral femoral condyle. With increasing knee flexion, the vector force, resulting from the tension of the quadriceps and the traction of the patellar tendon, pushes the patella in the trochlear groove, making it less vulnerable to lateral dislocations. Instead, a dysplastic trochlea, with flattening of the lateral facet, is unable to withstand such lateral force exerted even at low degrees of flexion. The vastus medialis obliquus (VMO) muscle contributes significantly to joint stability, acting as a dynamic stabilizer of the patellofemoral joint. A decrease in the strength of the VMO can compromise the force required to displace the patella laterally, although this does not necessarily determine a lateral displacement in the absence of other predisposing factors.

The Medial Patellofemoral Ligament (MPFL) is the primary passive constraint of the patellofemoral joint; it provides between 50 and $60 \%$ of the resistance to lateral patellar displacement during early knee flexion $\left(0-30^{\circ}\right)$. Moreover, the distance be- tween the vertical line through the center of gravity of the body and the axis of instantaneous rotation of the joint is one of the most important variables in the estimation of the forces acting on the patella ${ }^{8-24}$.

\section{Key points:}

- The joint geometry, the action of the muscles that act on the patella, the alignment of the lower limb, and the passive constraint exerted by the surrounding soft tissues are the principal stabilizers of the patellofemoral joint

- The patellofemoral joint forces depend on the strength of the quadriceps and of the patellar tendon, the degree of the knee flexion, the distance between the vertical line through the center of gravity of the body and the axis of the instantaneous rotation.

\section{Traumatic mechanism}

Acute patellar dislocation is a traumatic event characterized by complete loss of articular relationship between the patella and the femoral trochlea. It occurs almost exclusively in the lateral direction. Medial dislocation is practically exclusively iatrogenic, usually from a failed surgical lateral retinaculum release or a reconstruction of the medial patellofemoral ligament which has been tensioned too much. The traumatic event is frequently indirect (in $93 \%$ of cases) and occurs during sports practice, as a result of movements of knee flexion with valgus stress and added torsional forces that develop at the knee. However, the dislocation can also be secondary to direct trauma caused by a tangential force, which produces a lateral dislocation. Acute dislocation of the patella is a leading cause of knee haemarthrosis, second only to a lesion of the anterior cruciate ligament. In case of concomitant osteochondral lesion, fat droplets will be visible in the blood. In $80 \%$ of patients, the dislocation resolves spontaneously; in the remaining $20 \%$ of patients, the knee is typically kept in a flexed position, and appears deformed from the lateral displacement of the patella. Major and minor anatomical predisposing factors can be identified. Partial or complete tear of the medial patellofemoral ligament is detectable in $94-100 \%$ of patients, and some Authors have suggested that the dislocation itself is impossible without lesion of this anatomical structure. Although the MPFL is the medial structure more often involved, the trauma can injure the other structures of the retinaculum, such as the medial patellotibial ligament (MPTL), the superficial medial collateral ligament (MCL), and, more deeply, the medial patellomeniscal ligament (MPML). The post-traumatic marrow edema is usually seen in the femoral condyle in 80 $100 \%$ of patients, while in $41-61 \%$ of patients it is detectable even at the level of the inferior-medial aspect of the patella. Osteochondral lesions are more common on the patellar $(70 \%)$ rather than in femoral $(40 \%)$ articular surface, and can result in intra-articular loose bodies in 1/3 of patients ${ }^{25-39}$. 
Key points:

- The knee flexion with a valgus stress is the typical mechanism underlying patellar dislocation.

- Acute dislocation of the patella is a leading cause of knee haemarthrosis

- A partial or complete tear of the medial patellofemoral ligament (MPFL) is detectable in 94$100 \%$ of patients

- The trauma can injure the other structures of the medial patellar retinaculum (e.g., MPTL, MCL, MPML)

- The impact of the inferior-medial aspect of the patella on the anterolateral area of the lateral femoral condyle may cause bruising and osteochondral lesions, most frequently on the patellar than on the femoral surface.

\section{Clinical tests}

Patellar dislocations are usually diagnosed on the basis of medical history and clinical examination. A variety of clinical tests has been described for evaluating the patellofemoral instability. Although physical examination is considered of paramount importance in the diagnosis of patellofemoral disease, the evidences in support of clinical tests are lacking and methodologically limited. Currently, there is no scientific evidence supporting the use of a specific test, and further studies are needed to support their appropriateness in assessing patellofemoral instability ${ }^{40-52}$.

\section{Level of recommendation: $C$}

Key points:

The most reliable and sensitive clinical tests for the proper evaluation of the patellofemoral joint instability are:

- The Fairbanks sign (apprehension test)

- The Bassett's Sign for medial patellofemoral ligament

- The Gravity subluxation test, for medial patellar subluxation

- The Patellar Glide Test

- The Patellar Tilt Test

- The Quadriceps Pull Test.

\section{Imaging}

Conventional radiographs ( $X$-Ray) should be performed in all patients with patellar dislocation suspicion, and the presence of a visible osteochondral fracture on conventional radiography is plausibly suggestive of a cartilage injury.

Ultrasound: its use for after acute patellar dislocation is not validated.

Magnetic Resonance Imaging (MRI) in acute lateral dislocations of the patella can identify lesions of the medial retinaculum, MPFL and vastus medialis oblique muscle. A concave deformation of the inferomedial portion of the patella could represent a specific sign of a primitive lateral patellar dislocation.

Dynamic MRI can be used to study dynamically the patellofemoral joint.

$C T$ can be used to confirm osteochondral fracture and to evaluate the bony risk factors predisposing a patient to a dislocation ${ }^{53-62}$.
Level of recommendation: $B$

Key points:

- MRI, CT, plain radiography and ultrasound have advantages and disadvantage in the instrumental diagnosis of the first episode of dislocation of the patella. None has sensitivity and specificity to be recommended as the only imaging investigation.

\section{Conservative treatment}

The initial approach to the dislocation of the patella is the reduction of the dislocation and the pharmacological management of pain and inflammation. Surgery after the first episode is controversial, even in patients who have a clear high risk of recurrence. Early immobilization of the knee and the use of crutches is always to be provided immediately after the reduction. It may be useful to administer dietary supplements of chondroitin sulfate and glucosamine, natural elements necessary for the biosynthesis of proteoglycans essential for the health of joint cartilage ${ }^{63-66}$.

\section{Level of recommendation: $D$}

Key points:

- Reduction of the dislocation and pharmacological management of pain and inflammation are the initial approach in patients with acute dislocation of the patella

- Reduction of the dislocation is usually simple and safe which, however, must be performed by a qualified physician

- Any associated lesions must be excluded before initiating reduction

- Early immobilization of the knee and use of crutches is to be provided after the reduction.

\section{Rehabilitation approaches}

Conservative management following the first episode of a patellar dislocation is recommended when imaging does not detect chondral lesions, osteochondral fragments or serious injuries of the parapatellar ligament complex. The effective recovery as a result of conservative treatment has yet to be established, since some studies show that about $1 / 3$ of patients treated conservatively present limitation of activities after 6 months to 3 years, even in the absence of a redislocation. Despite the lack of rigorous clinical evidence, many reviews report opinions and recommendations derived from the expertise and experience of the Authors. Therapeutic exercise seems to play a primary role in each stage of recovery. At present, there is no evidence about the choice of exercises ${ }^{67-81}$.

\section{Level of recommendation: $C$} Key points:

- There is no adequate clinical evidence regarding the most effective modalities for conservative management following the first episode of patellar dislocation

- Therapeutic exercise plays a primary role in each stage of patient recovery (initial tissue protection, pain reduction, recovery of joint movements, muscle bulk and knee function, prevention of patel- 
lofemoral instability and of redislocation)

- There is no evidence on the modality of therapeutic exercise (closed or open kinetic chain, preferential degrees of knee joint, vastus medialis obliquus muscle or general quadriceps strengthening, use of dynamic neuromuscular stabilization exercises, association or not with facilitation techniques, or taping, physical modalities).

\section{Physical modalities}

Physical and instrumental therapies are commonly used in the various phases of the treatment of patients who sustained a first episode of patellar dislocation. However, their actual clinical efficacy has never been demonstrated in prospective or retrospective studies, and the most "correct" way in which they should be used is at best unclear. Cryotherapy is useful in the first 48 hours of injury, but it can be used also in the following 3-4 weeks to address the joint effusion and the pain after exercise therapy and loading. Electrostimulation can prevent muscle atrophy, promote muscle strengthening, and facilitate functionally useful movements ${ }^{82-90}$.

\section{Level of recommendation: $D$} Key points:

- At present, there are no safe clinical evidences on physical modalities in the management of patients following their first episode of patellar dislocation.

\section{Taping, bracing and casting}

Taping is used after the first 6 weeks to reduce pain, facilitate the recruitment of the $\mathrm{VMO}$, and as psychological support. Casting has been advocated to allow healing of the medial retinaculum and of the MPFL, but prolonged immobilization results in adverse effects on ligament, bone, cartilage and muscles. The use of braces or tapes could offer faster functional recovery, but with a longer time for MPFL healing ${ }^{91-93}$.

\section{Level of recommendation: $D$}

Key points:

- There is no evidence regarding the choice between the taping, bracing or complete immobilization is a cast in the management of patients with their first patellar dislocation

- Taping seems to help with symptoms, but has no effect on the patellar realignment

- Prolonged immobilisation has negative effects on the ligaments, cartilage, bone and muscles.

\section{Proximal realignment surgery}

The concept of proximal realignment and quadriceps plasty were introduced in 1975 to treat recurrent subluxation of the patella. The procedure was modified by Insall, who used an isolated proximal realignment. Proximal realignment remains a valuable intervention for some patients with patellar instability, but it is not used in patients with first time patellar dislocation ${ }^{94-97}$. Level of recommendation: $D$
Key points:

- At present, there is no evidence in favour of isolated proximal realignment and quadriceps plasty for patients following their first episode of patellar dislocation.

\section{Lateral retinacular release}

Lateral retinacular release is improperly used in patients with patellar instability. From a biomechanical point of view, isolated lateral release cannot correct the causes of patellar instability (trochlear hypoplasia, vastus medialis atrophy, medial ligamentous laxity). The literature on the results of lateral release is based on retrospective studies with short follow-up and low level of evidence. In a systemic review, Lattermann confirmed that the medium and long-term results of this procedure are extremely unsatisfactory, and that the lateral release has no indication in the management of acute and chronic patellar instability. An excessive lateral release can cause iatrogenic patellar pathologies. In particular, a release can determine medial instability if performed too proximal to the upper border of the patella. In the presence of a cartilaginous lesion of the medial patella, release may increase the load in this area, resulting in worsening of the lesion. Also, if the patient has an increased $Q$ angle, isolated release can increase this angle, thus increasing instability symptoms ${ }^{98-105}$.

\section{Level of recommendation: $B$}

Key points:

- Isolated lateral release is not indicated for the management of patients with acute or recurrent patellar dislocation

- Isolated lateral release is contraindicated in patients following an acute dislocation of the patella, since this procedure does not address the cause of dislocation, but rather weakens the stabilizing forces on the patella.

\section{Three-in-one precedure (lateral release, proximal vastus medialis realigment and plasty, and medial transfer of the medial one third of the patellar ten- don)}

The "three-in-one" procedure is indicated for recurrent dislocation of the patella in skeletally immature children and adolescents, who do not respond to conservative treatment and have a tilt associated to excessive lateralization of the patella. At present, there is no evidence in favour of this surgical procedure for the management of patients following their first episode of patellar dislocation ${ }^{106-109}$.

\section{Level of recommendation: $B$}

Key points:

- The "three-in-one" procedure is indicated for recurrent patellar dislocation

- It can be performed in the skeletally immature patients, avoiding damage to the proximal epiphysis of the tibia (not involved in the surgical procedure), and it does not preclude to perform additional stabilization interventions when required. 


\section{Isolated medial patellofemoral ligament (MPFL) re- construction}

An anatomical repair MPFL is necessary to prevent recurrence. The high success rate $(79.2 \%)$ and the low rate of recurrence with this procedure probably depend on correct selection of patients ${ }^{110-119}$.

Level of recommendation: $B$

Key points:

- Several techniques have been described to reconstruct the MPFL, and at present there is no clear consensus on the best surgical procedure to reconstruct it

- Isolated MPFL reconstruction appears to be adequate also in the acute phase.

\section{Tibial tubercle osteotomy}

Distal realignment procedures are indicated in patients with lateralization of the tibial tuberosity. These techniques should be considered when recurrences are caused by skeletal deformities related to malalignment of the extensor apparatus. Bone realignments allow the correction of patellar "maltracking", and the management of symptoms associated to this condition ${ }^{120-122}$.

\section{Level of recommendation: $C$} Key points:

- Distal realignment techniques should not be used in the management of patients following their first episode of dislocation

- This procedure could be considered only following their first episode of patellar dislocation in skeletally mature patients, and in patients with well documented lateralization of the tibial tuberosity.

\section{Trochleoplasty}

It aims to change the shape of the distal femur in those patients in whom recurrent patellar instability is associated with trochlear dysplasia. This procedure is not indicated following the first episode of dislocation of the patella, and it should only be performed in patients with recurrent dislocation. Also, in the presence of severe trochlear dysplasia, it may also be possible to obtain good results with other procedures, avoiding the knee rigidity which typically follows a trochleoplasty. Trochleoplasty carries a high risk of cartilage damage and of permanent modifications of the knee joint kinematics. All these factors are critical, and they may result in the development of early osteoarthritis ${ }^{123-130 .}$

\section{Level of recommendation: $B$}

Key points:

- Trochleoplasty does not play a role in patients following their first episode of dislocation of the patella

- It must be reserved to selected patients, particularly when revision surgery is needed.

\section{Post-surgical rehabilitation}

Recovery after surgery depends on adequate postoperative rehabilitation. Having different surgical techniques implies that different rehabilitation protocols should be used, each specific to each approach. However, currently, there are no standardized protocols for rehabilitation following surgery for this condition $^{131-136}$.

\section{Level of recommendation: $D$}

Key points:

- Post-surgical rehabilitation is critical to recover function of the knee joint

- It is not possible to determine which is the most suitable rehabilitation approach for patients undergoing surgery, as there is lack of adequate clinical studies

- The transition between the different rehabilitative phases and the return to full activity should be based on functional rather than on time criteria.

\section{Return to sport}

Return to their sport at the same level as before the dislocation is the goal of injured athletes. Nevertheless, there is a lack of studies on the return to the sport after this traumatic event or after surgery ${ }^{137-145}$.

\section{Level of recommendation: $D$}

Key points:

- There are few studies in the literature on return to sport after the first episode of patellar dislocation

- To evaluate the suitability of a patient to return to sport, strength (strength limb symmetry index), functional performance tests, and tests to assess the dynamic stability of the knee and the trunk can be used. None should be used in isolation

- Early introduction to sports-specific exercises can improve self-confidence, can increase compliance and facilitate a more rapid and safe return to the sport practice.

\section{Author contributions}

\section{Coordinator \\ Mario Vetrano, Francesco Oliva.}

\section{Control Group}

Nicola Maffulli, Calogero Foti, Stefano Masiero, Leonardo Osti, Alfredo Schiavone Panni, Umberto Tarantino, Maria Chiara Vulpiani, Andrea Ferretti.

\section{Group of the experts}

Salvatore Bisicchia, Angelo De Carli, Luigi Di Lorenzo, Alfonso Forte, Antonio Frizziero, Alessio Giai Via, Bernardo Innocenti, Giuseppe Longo Umile, Asmaa Mahmoud, Johnny Padulo, Fabrizio Perroni, Eleonora Piccirilli, Carlo Ramponi. 


\section{Group of preparation and evaluation of the litera- ture}

Alessandra Berton, Michela Bossa, Davide Erroi, Giuseppe Gasparre, Daniele Mazza, Simone Natali, Christian Notarangelo, Leonardo Pellicciari, Giuseppe Salvatore, Tania Suarez, Filippo Vittadini.

\section{References}

1. Sillanpää $P$, Mattila VM, livonen $T$, Visuri $T$, Pihlajamäki H. Incidence and risk factors of acute traumatic primary patellar dislocation. Med Sci Sports Exerc. 2008;40(4):606-611.

2. Hsiao M, Owens BD, Buks R, Studvant RX, Kameron KL. Incidence of traumatic patellar dislocation among activity-duty United States military service members. Am J Sports Med. 2010;38(10):1997-2004.

3. Fithian DC, Paxton EW, Stone ML, Silva P, Davis DK, Elias DA, White LM. Epidemiology and natural history of acute patellar dislocation. Am J Sports Med. 2004;32(5):1114-1121 .

4. Paakkala $A$, Sillanpää $P$, Huhtala $H$, Paakkala $T$, Mäenpää $H$. Bone bruise in acute traumatic patellar dislocation: volumetric magnetic resonance imaging analysis with follow-up mean of 12 months. Skeletal Radiol. 2010;39(7):675-82.

5. Nikku R, Nietosvaara Y, Aalto K, Kallio PE. Operative treatment fo primary patellar dislocation does not improve mediumterm outcome: a 7 year follow-ip report and risk analysis of 127 randomized patients. Acta Orthop. 2005;76(5):699-704.

6. Palmu S, Kallio PE, Donell ST, Helenius I, Nietosvaara Y. Acute patellar dislocation in children and adolescents: a randomized clinical trial. J Bone Joint Surg Am. 2008;90(3):463470.

7. Apostolovic M, Vukomanovic B, Slavkovic N, Vuckovic V, Vukcevic M, Djuricic G, Kocev N. Acute patellar dislocation in adolescents: operative versus non operative treatment. Int Orthop. 2011;35(10):1483-1487.

8. Amis AA. Current concepts on anatomy and biomechanics of patellar stability. Sports Med Arthrosc. 2007;15(2):48-56.

9. Feller JA, Amis AA, Andrish JT, Arendt EA, Erasmus PJ, Powers $\mathrm{CM}$. Surgical biomechanics of the patellofemoral joint. Arthroscopy. 2007:23(5):542-553.

10. Schindler OS, Scott WN. Basic kinematics and biomechanics of the patello-femoral joint. Part1: The native patella. Acta Orthop Belg. 2011;77(4):421-431.

11. Hehne HJ. Biomechanics of the patellofemoral joint and its clinical relevance. Clin Orthop Relat Res. 1990;(258):73-85

12. Ficat $P$, Hungerford $D S$. Disorders of the Patello-femoral Joint. Williams \& Wilkins, Baltimore, 1977.

13. Goodsir J. On the mechanism of the knee joint. In: Turner W (ed). The Anatomical Memoirs of John Goodsir. Vol. 2. Adams and Charles Black, Edinburgh. 1868;231-245.

14. Panni AS, Cerciello S, Maffulli N, Di Cesare M, Servien E, Neyret P. Patellar shape can be a predisposing factor in patellar instability. Knee Surg Sports Traumatol Arthrosc. 2011; 19(4):663-670.

15. Senavongse $\mathrm{W}, \mathrm{Amis} \mathrm{AA}$. The effects of articular, retinacular, or muscular deficiencies on patellofemoral joint stability: A biomechanical study in vitro. J Bone Joint Surg Br. 2005;87 (4):577-582.

16. Beaconsfield T, Pintore E, Maffulli N, Petri GJ. Radiological measurements in patellofemoral disorders. A review. Clin Orthop Relat Res. 1994;(308):18-28.

17. Goutallier D, Bernageau J, Lecudonnec B. The measurement of the tibial tuberosity. Patella groove distanced technique and results (author's transl). Rev Chir Orthop Reparatrice Appar Mot. 1978;64(5):423-428.

18. Arendt EA, Fithian DC, Cohen E. Current concepts of lateral patella dislocation. Clin Sports Med. 2002;21(3):499-519.

19. Desio SM, Burks RT, Bachus KN. Soft tissue restraints to lateral patellar translation in the human knee. Am J Sports Med. 1998;26(1):59-65.

20. Andriacchi TP, Andersson GB, Fermier RW, Stern D, Galante JO. A study of lower limb mechanics during stair climbing. J Bone Joint Surg Am. 1980;62(5):749-757.

21. Paul JJ. Force actions transmitted in the knee of normal subjects and by prosthetic joint replacements. In: The Medical Engineering Working Party (ed). Total Knee Replacement. Mechanical Engineering Publications limited, London. 1974;126131.

22. Bresler B, Frankel JP. The forces and moment in the leg during level walking. Trans Am Society of Medical Engineers. 1950;72:27-36.

23. Dahlqvist NJ, Mayo P, Seedhom BB. Forces during squatting and rising from a deep squat. Eng Med. 1982;11(2):69-76.

24. Winter DA. Moments of force and mechanical power in jogging. J Biomech. 1983;16(1):91-97.

25. Wilk KE, Davies GJ, Mangine RE, Malone TR. Patellofemoral disorders: a classification system and clinical guidelines for nonoperative rehabilitation. J Orthop Sports Phys Ther. 1998; 28(5):307-322.

26. Le Corroller T, Dediu M, Champsaur P. Transient medial patellar dislocation: injury patterns at US and MR imaging. Skeletal Radiol. 2009;38(5):519-523.

27. Sillanpää P, Mattila VM, livonen T, Visuri T, Pihlajamäki H. Incidence and risk factors of acute traumatic primary patellar dislocation. Med Sci Sports Exerc. 2008;40(4):606-611.

28. Atkin DM, Fithian DC, Marangi KS, Stone ML, Dobson BE, Mendelsohn $\mathrm{C}$. Characteristics of patients with primary acute lateral patellar dislocation and their recovery within the first 6 months of injury. Am J Sports Med. 2000;28(4):472-479.

29. Fithian DC, Paxton EW, Stone ML, Silva P, Davis DK, Elias DA, White LM. Epidemiology and natural history of acute patellar dislocation. Am J Sports Med. 2004;32(5):1114-1121.

30. Duthon VB. Acute traumatic patellar dislocation. Orthop Traumatol Surg Res. 2015;101(1 Suppl):S59-67.

31. Stefancin JJ, Parker RD. First-time traumatic patellar dislocation: a systematic review. Clin Orthop Relat Res. 2007;455:93101.

32. Lewallen L, Mclntosh A, Dahm D. First-Time Patellofemoral Dislocation: Risk Factors for Recurrent Instability. J Knee Surg. 2015;28(4):303-309.

33. Dejour H, Walch G, Nove-Josserand L, et al. Factors of patellar instabil-ity: an anatomic radiographic study. Knee Surg Sports Traumatol Arthrosc. 1994;2(1):19-26.

34. Warren LF, Marshal Jl. Supporting structures and layers on the medial side of the knee: an anatomical analysis. J Bone Joint Surg Am. 1979;61(1):56-62.

35. Nomura E. Classification of lesions of the medial patellofemoral ligament in patellar dislocation. Int Orthop. 1999; 23(5):260-263.

36. Sallay PI, Poggi J, Speer KP, Garrett WE. Acute dislocation of the patella: a correlative pathoanatomic study. Am J Sports Med. 1996;24(1):52-60.

37. Kirsch MD, Fitzgerald SW, Friedman H, Rogers LF. Transient lateral patellar dislocation: diagnosis with MR imaging. AJR Am J Roentgenol. 1993;161(1):109-113.

38. Spritzer CE, Courneya DL, Burk DL Jr, Garrett WE, Strong JA. Medial retinacular complex injury in acute patellar dislocation: MR findings and surgical implications. AJR Am J Roentgenol. 1997;168(1):117-122.

39. Sanders TG, Morrison WB, Singleton BA, Miller MD, Cornum KG. Medial patellofemoral ligament injury following acute transient dislocation of the patella: MR findings with surgical correlation in 14 patients. J Comput Assist Tomogr. 2001;2 5(6): 957-962. 
40. DeHaven KE, Lintner DM. Athletic injuries: comparison by age, sport, and gender. Am J Sports Med. 1986;14(3):218224.

41. Mulford JS, Wakeley CJ, Eldridge JD. Assessment and management of chronic patellofemoral instability. J Bone Joint Surg Br. 2007;89(6):709-716.

42. Stefancin JJ, Parker RD. First-time traumatic patellar dislocation: a systematic review. Clin Orthop Relat Res. 2007;455:93101.

43. Oliva F, Ronga M, Longo UG, Testa V, Capasso G, Maffulli N. The 3-in-1 procedure for recurrent dislocation of the patella in skeletally immature children and adolescents. Am J Sports Med. 2009;37(9):1814-1820.

44. Smith TO, Davies L, O'Driscoll ML, Donell ST. An evaluation of the clinical tests and outcome measures used to assess patellar instability. Knee. 2008;15(4):255-262.

45. Buchner M, Baudendistel B, Sabo D, Schmitt H. Acute traumatic primary patellar dislocation: long-term results comparing conservative and surgical treatment. Clin J Sport Med. 2005; 15(2):62-66.

46. Beasley LS, Vidal AF. Traumatic patellar dislocation in children and adolescents: treatment update and literature review. Curr Opin Pediatr. 2004;16(1):29-36.

47. Hawkins RJ, Bell RH, Anisette G. Acute patellar dislocations. The natural history. Am J Sports Med. 1986;14(2):117-120.

48. Boden BP, Pearsall AW, Garrett WE Jr. Feagin JA Jr. Patellofemoral Instability: Evaluation and Management. J Am Acad Orthop Surg. 1997;5(1):47-57.

49. Cosgarea AJ, Browne JA, Kim TK, McFarland EG. Evaluation and management of the unstable patella. Phys Sportsmed. 2002;30(10):33-40.

50. Maffulli N, Longo UG, Gougoulias N, Caine D, Denaro V. Sport injuries: a review of outcomes. Br Med Bull. 2011;97:47-48.

51. Maffulli N, Longo UG, Gougoulias N, Loppini M, Denaro V. Long-term health outcomes of youth sports injuries. $\mathrm{Br} J$ Sports Med. 2010;44(1):21-25.

52. Sallay PI, Poggi J, Speer KP, Garrett WE. Acute dislocation of the patella. A correlative pathoanatomic study. Am J Sports Med. 1996;24(1):52-60.

53. Nonweiler DE, DeLee JC. The diagnosis and treatment of medial subluxation of the patella after lateral retinacular release. Am J Sports Med. 1994;22(5):680-686.

54. Ando T, Hirose H, Inoue M, Shino K, Doi T. A new method using computed tomographic scan to measure the rectus femoris-patellar tendon Q-angle comparison with conventional method. Clin Orthop Relat Res. 1993;(289):213-219.

55. Shakespeare D, Fick D. Patellar instability-can the TT-TG distance be measured clinically? Knee. 2005;12(3):201-204.

56. Mehta VM, Inoue M, Nomura E, Fithian DC. An algorithm guiding the evaluation and treatment of acute primary patellar dislocations. Sports Med Artrhrosc. 2007;15(2):78-81.

57. Malghem J, Maldague B. Depth insufficiency of the proximal trochlear groove on lateral radiographs of the knee: relation to patellar dislocation. Radiology. 1989;170(2):507-510.

58. Nietosvaara $\mathrm{Y}$, Aalto K. The cartilaginous femoral sulcus in children with patellar dislocation: an ultrasonographic study. J Pediatr Orthop. 1997;17(1):50-53.

59. Elias DA, White LM, Fithian DC. Acute lateral patellar dislocation at MR imaging: injury patterns of medial patellar soft-tissue restraintsand osteochondral injuries of the inferomedial patella. Radiology. 2002;225(3):736-743.

60. Balcarek P, Ammon J, Frosch S, Walde TA, Schüttrumpf JP, Ferlemann KG, Lill H, Stürmer KM, Frosch KH. Magnetic resonance imaging characteristics of the medial patellofemoral ligament lesion in acutelateral patellar dislocations considering trochlear dysplasia, patella alta, and tibial tuberosity-trochleargroove distance. Arthroscopy. 2010;26(7):926-935.

61. Shellock FG, Mink JH, Deutsch AL, Fox JM. Patellar tracking abnormalities: clinical experience with kinematic MR imaging in 130 patients. Radiology. 1989;172(3):799-804.

62. Dejour D, Ferrua P, Ntagiopoulos PG, Radier C, Hulet C, Rémy F, Chouteau J, Chotel F, Boisrenoult P, Sebilo A, Guilbert S, Bertin D, Ehkirch FP, Chassaing V; French Arthroscopy Society (SFA). The introduction of a new MRI index to evaluate sagittal patellofemoral engagement. Orthop Traumatol Surg Res. 2013;99(8 Suppl):S391-398.

63. Mehta VM, Inoue M, Nomura E, Fithian DC. An algorithm guiding the evaluation and treatment of acute primary patellar dislocations. Sports Med Artrhrosc. 2007;15(2):78-81.

64. Smith TO, Donell S, Song F, Hing CB. Surgical versus nonsurgical interventions for treating patellar dislocation. Cochrane Database Syst Rev. 2015;2:CD008106.

65. Hawkins RJ, Bell RH, Anisette G. Acute patellar dislocations The natural history. Am J Sports Med. 1986;14(2):117-120.

66. van Gemert JP, de Vree LM, Hessels RA, Gaakeer MI. Patellar dislocation: cylinder cast, splint or brace? An evidencebased review of the literature. Int J Emerg Med. 2012; 5(1):45

67. Stefancin JJ, Parker RD. First-time traumatic patellar dislocation: a systematic review. Clin Orthop Relat Res. 2007;455:93101.

68. Palmu S, Kallio PE, Donell ST, Helenius I, Nietosvaara Y. Acute patellar dislocation in children and adolescents: a randomized clinical trial. J Bone Joint Surg Am. 2008: 90(3):463470.

69. Regalado G, Lintula H, Kokki H, Kröger H, Väätäinen U, Eskelinen M. Six-year outcome after non-surgical versus surgical treatment of acute primary patellar dislocation in adolescents: a prospective randomized trial. Knee Surg Sports Traumatol Arthrosc. 2016;24(1):6-11.

70. Cheng B, Wu X, Ge H, Qing Sun Y, Zhang Q. Operative versus conservative treatment for patellar dislocation: a metaanalysis of 7 randomized controlled trials. Diagn Pathol. 2014;18;9:60.

71. Zheng X, Kang K, Li T, Lu B, Dong J, Gao S. Surgical versus non-surgical management for primary patellar dislocations: an up-to-date meta-analysis. Eur J Orthop Surg Traumatol. 2014;24(8):1513-1523.

72. Smith TO, Donell S, Song F, Hing CB. Surgical versus nonsurgical interventions for treating patellar dislocation. Cochrane Database Syst Rev. 2015;2:CD008106.

73. Atkin DM, Fithian DC, Marangi KS, Stone ML, Dobson BE, Mendelsohn $\mathrm{C}$. Characteristics of patients with primary acute lateral patellar dislocation and their recovery within the first 6 months of injury. Am J Sports Med. 2000;28(4):472-479.

74. Magnussen RA, Verlage M, Stock E, Zurek L, Flanigan DC, Tompkins M, Agel J, Arendt EA. Primary patellar dislocations without surgical stabilization or recurrence: how well are these patients really doing? Knee Surg Sports Traumatol Arthrosc. 2015.

75. Respizzi S, Cavallin R. First patellar dislocation: from conservative treatment to return to sport. Joints. 2014;2(3):141-145.

76. Kang HJ, Wang F, Chen BC, Zhang YZ, Ma L. Non-surgical treatment for acute patellar dislocation with special emphasis on the MPFL injury patterns. Knee Surg Sports Traumatol Arthrosc. 2013;21(2):325-331.

77. Smith TO, Davies L, Chester R, Clark A, Donell ST. Clinical outcomes of rehabilitation for patients following lateral patellar dislocation: a systematic review. Physiotherapy. 2010;96(4): 269-281.

78. Smith TO, Chester R, Clark A, Donell ST, Stephenson R. A national survey of the physiotherapy management of patients following first-time patellar dislocation. Physiotherapy. 2011; 97(4):327-338.

79. Smith TO, Chester R, Cross J, Hunt N, Clark A, Donell ST. Rehabilitation following first-time patellar dislocation: a randomised controlled trial of purported vastus medialis obliquus 
muscle versus general quadriceps strengthening exercises. Knee. 2015;22(4):313-320.

80. Fukuda TY, Rossetto FM, Magalhães E, Bryk FF, Lucareli PR, de Almeida Aparecida Carvalho N. Short-term effects of hip abductors and lateral rotators strengthening in females with patellofemoral pain syndrome: a randomized controlled clinical trial. J Orthop Sports Phys Ther. 2010;40(11):736-742.

81. Nakagawa TH, Muniz TB, Baldon Rde M, Dias Maciel C, de Menezes Reiff RB, Serrão FV. The effect of additional strengthening of hip abductor and lateral rotator muscles in patellofemoral pain syndrome: a randomized controlled pilot study. Clin Rehabil. 2008;22(12):1051-1060.

82. Hing CB, Smith TO, Donell S, Song F. Surgical versus nonsurgical interventions for treating patellar dislocation. Cochrane Database Syst Rev. 2011;(11):CD008106.

83. Tsai $\mathrm{CH}$, Hsu CJ, Hung $\mathrm{CH}$, Hsu HC. Primary traumatic patellar dislocation. J Orthop Surg Res. 2012;7:21.

84. Jain NP1, Khan N, Fithian DC. A treatment algorithm for primary patellar dislocations. Sports Health. 2011;3(2):170-174.

85. Smith TO, McNamara I, Donell ST. The contemporary management of anterior knee pain and patellofemoral instability. Knee. 2013;20 Suppl 1:S3-S15.

86. McConnell J. Rehabilitation and nonoperative treatment of patellar instability. Sports Med Arthrosc. 2007;15(2):95-104

87. Duthon VB. Acute traumatic patellar dislocation. Orthop Traumatol Surg Res. 2015;101(1 Suppl):S59-67.

88. Saccomanno MF, Sircana G, Fodale M, Donati F, Milano G. Surgical versus conservative treatment of primary patellar dislocation. A systematic review and meta-analysis. Int Orthop. 2015.

89. Khormaee S, Kramer DE, Yen YM, Heyworth BE. Evaluation and management of patellar instability in pediatric and adolescent athletes. Sports Health. 2015;7(2):115-123.

90. Bitar AC, Demange MK, D'Elia CO, Camanho GL. Traumatic patellar dislocation: nonoperative treatment compared with MPFL reconstruction using patellar tendon. Am J Sports Med. 2012;40(1):114-122.

91. Rood A, Boons H, Ploegmakers J, van der Stappen W, Koëter S. Tape versus cast for non-operative treatment of primary patellar dislocation: a randomized controlled trial. Arch Orthop Trauma Surg. 2012;132(8):1199-1203.

92. Armstrong BM, Hall M, Crawfurd E, Smith TO. A feasibility study for a pragmatic randomised controlled trial comparing cast immobilisation versus no immobilisation for patients following first-time patellar dislocation. Knee. 2012;19(5):696702.

93. van Gemert JP, de Vree LM, Hessels RA, Gaakeer MI. Patellar dislocation: cylinder cast, splint or brace? An evidencebased review of the literature. Int J Emerg Med. 2012;5(1):45

94. Madigan R, Wissinger HA, Donaldson WF. Preliminary experience with a method of quadricepsplasty in recurrent subluxation of the patella. J Bone Joint Surg Am. 1975;57(5):600-607.

95. Insall J, Bullough PG, Burstein AH. Proximal "tube" realignment of the patella for chondromalacia patellae. Clin Orthop Relat Res. 1979;(144):63-69.

96. Abraham E, Washington E, Huang TL. Insall proximal realignment for disorders of the patella. Clin Orthop Relat Res. 1989;(248):61-65.

97. Scuderi G, Cuomo F, Scott WN. Lateral release and proximal realignment for patellar subluxation and dislocation. A longterm follow-up. J Bone Joint Surg Am. 1988;70(6):856-861 .

98. Schiavone Panni A, Cerciello S, Vasso M. Patellofemoral instability: surgical treatment of soft tissues. Joints. 2013;1 (1):34-39.

99. Merchant AC, Mercer RL. Lateral release of the patella. A preliminary report. Clin Orthop Relat Res. 1974;(103):40-45.

100. Verdonk P, Bonte F, Verdonk R. Lateral retinacular release. Orthopade. 2008;37(9):884-889.
101. Lattermann C, Drake GN, Spellman J. Lateral retinacular release for anterior knee pain: a systematic review of the literature. J Knee Surg. 2006;19(4):278-284.

102. Fithian DC, Paxton EW, Post WR, Panni AS; International Patellofemoral Study Group. Lateral retinacular release: a survey of the International Patellofemoral Study Group. Arthroscopy. 2004;20(5):463-468.

103. Kolowich PA, Paulos LE, Rosenberg TD, Farnsworth S. Lateral release of the patella: indications and contraindications. Am J Sports Med. 1990;18(4):359-365.

104. Panni AS, Vasso M, Cerciello $S$. Acute patellar dislocation. What to do? Knee Surg Sports Traumatol Arthrosc. 2013;21 (2):275-278.

105. Christoforakis J, Bull AM, Strachan RK, Shymkiw R, Senavongse W, Amis AA. Effects of lateral retinacular release on the lateral stability of the patella. Knee Surg Sports Traumatol Arthrosc. 2006;14(3):273-277.

106. Myers PT, Boume R, Bülow J. The "three-in-one" procedure for the unstable patella. J Bone Joint Surg. 1993;75-B Suppl $1: 62$.

107. Myers PT, Williams A, Dodds R, Bülow J. The three-in-one proximal and distal soft tissue patellar realignment procedure. Results, and its place in the management of patellofemoral instability. Am J Sports Med. 1999;27(5):575-579.

108. Luscombe KL, Maffulli N. The three in one procedure: how I do it. Surgeon. 2004;2(1):32-36.

109. Oliva F, Ronga M, Longo UG, Testa V, Capasso G, Maffulli N. The 3-in-1 procedure for recurrent dislocation of the patella in skeletally immature children and adolescents. Am J Sports Med. 2009;37(9):1814-1820.

110. Carmont MR, Maffulli N. Medial patellofemoral ligament reconstruction: a new tecnique. BMC Musculoskelet Disord. 2007;8:22.

111. Ronga M, Oliva F, Longo G, Testa V, Capasso G, Maffulli N Isolated medial patellofemoral ligament reconstruction for recurrent patellar dislocation. Am J Sports Med. 2009;37 (9):1735-1742

112. Smirk $\mathrm{C}$, Morris $\mathrm{H}$. The anatomy and reconstruction of the medial patellofemorl ligament. Knee. 2003;10(3):221-227.

113. Elias JJ, Cosgarea AJ. Technical errors during medial patellofemoral ligament reconstruction could overload medial patellofemoral cartilage: a computational analysis. Am J Sports Med. 2006;34(9):1478-1485.

114. Drez D Jr, Edwards TB, Williams CS. Results of medial patellofemoral ligament reconstruction in the treatment of patellar dislocation. Arthroscopy. 2001;17(3):298-306.

115. Schöttle PB, Fucentese SF, Romero J. Clinical and radiological outcome of medial patellofemoral ligament reconstruction with a semitendinosus autograft for patella instability. Knee Surg Sports Traumatol Arthrosc. 2005;13(7):516-521.

116. Palmu S, Kallio PE, Donell ST, Helenius I, Nietosvaara $Y$. Acute patellar dislocation in children and adolescents: a randomized clinical trial. J Bone Joint Surg Am. 2008 Mar;90 (3):463-470.

117. Nietosvaara $Y$, Aalto $K$, Kallio PE. Acute patellar dislocation in children: incidence and associated osteochondral fractures. $J$ Pediatr Orthop. 1994;14(4):513-515.

118. Nikku R, Nietosvaara $Y$, Aalto $K$, Kallio PE. Operative treatment of primary patellar dislocation does not improve mediumterm outcome: A 7-year follow-up report and risk analysis of 127 randomized patients. Acta Orthop. 2005;76(5):699-704.

119. LeGrand AB, Greis PE, Dobbs RE, Burks RT. MPFL reconstruction. Sports Med Arthrosc. 2007;15(2):72-77.

120. Hauser EW. Total tendon transplant for splitting patella. Surg Gynecol Obstet. 1938;66:199.

121. Fulkerson JP. Anteromedialization of the tibial tuberosity for patellofemoral malalignment. Clin Orthop Relat Res. 1983 (177):176-181. 
122. Payne J, Rimmke N, Schmitt LC, Flanigan DC, Magnussen RA. The Incidence of Complications of Tibial Tubercle Osteotomy: A Systematic Review. Arthroscopy. 2015;31(9): 1819-1825.

123. Ntagiopoulos PG, Dejour D. Current concepts on trochleoplasty procedures for the surgical treatment of trochlear dysplasia. Knee Surg Sports Traumatol Arthrosc. 2014;22 (10):2531-2539.

124. Beaufils P, Thaunat M, Pujol N, Scheffler S, Rossi R, Carmont M. Trochleoplasty in major trochlear dysplasia: current concepts. Sports Med Arthrosc Rehabil Ther Technol. 2012; 4:7.

125. Bollier M, Fulkerson JP. The role of trochlear dysplasia in patellofemoral instability. J Am Acad Orthop Surg. 2011; 19(1):8-16.

126. Duncan ST, Noehren BS, Lattermann C. The role of trochleoplasty in patellofemoral instability. Sports Med Arthrosc. 2012;20(3):171-180.

127. Dejour H, Walch G, Neyret P, Adeleine P. Dysplasia of the femoral trochlea. Rev Chir Orthop Reparatrice Appar Mot. 1990;76(1):45-54.

128. Schöttle PB, Fucentese SF, Pfirrmann C, Bereiter H, Romero J. Trochleaplasty for patellar instability due to trochlear dysplasia: A minimum 2-year clinical and radiological follow-up of 19 knees. Acta Orthop. 2005;76(5):693-698.

129. Biedert R, Zaffagnini S, Dejour D, Arendt EA. Patellofemoral Pain, Instability, and Arthritis. Berlin: Springer-Verlag. Trochlear lengthening osteotomy with or without elevation of the lateral trochlear facet. 2010;209-215.

130. Peterson L, Karlsson J, Brittberg M. Patellar instability with recurrent dislocation due to patellofemoral dysplasia. Results after surgical treatment. Bull Hosp Jt Dis Orthop Inst. 1988;48: 130-139.

131. Smith TO, Donnell ST. The rehabilitation following medial patellofemoral ligament reconstructions. Int J Orthop Surg. 2007;8(1).

132. Akeson WH, Amiel D, Abel MF, Garfin SR, Woo SL. Effects of immobilization on joints. Clin Orthop Relat Res. 1987; (219): 28-37.

133. Häggmark $T$, Eriksson E. Cylinder or mobile cast brace after knee ligament surgery. A clinical analysis and morphologic and enzymatic studies of changes in the quadriceps muscle. Am J Sports Med. 1979;7(1):48-56.

134. Fisher B, Nyland J, Brand E, Curtin B. Medial patellofemoral ligament reconstruction for recurrent patellar dislocation: a systematic review including rehabilitation and return-to-sports efficacy. Arthroscopy. 2010;26(10):1384-1394.

135. Ahmad CS, Brown GD, Shubin Stein B. The docking technique for medial patellofemoral ligament reconstruction: Surgical technique and clinical outcome. Am J Sports Med. 2009;37:2021-2027.

136. Frizziero A, Trainito S, Oliva F, Nicoli Aldini N, Masiero S, Maffulli $\mathrm{N}$. The role of eccentric exercise in sport injuries rehabilitation. Br Med Bull. 2014;110(1):47-75.

137. Ménétrey J, Putman S, Gard S. Return to sport after patellar dislocation or following surgery for patellofemoral instability. Knee Surg Sports Traumatol Arthrosc. 2014;22(10):23202326.

138. Christiansen SE, Jacobsen BW, Lund B, Lind M. Reconstruction of the medial patellofemoral ligament with gracilis tendon autograft in transverse patellar drill holes. Arthroscopy. 2008; 24(1):82-87.

139. Gigante A, Enea D, Greco F, Bait C, Denti M, Schonhuber H, Volpi P. Distal realignment and patellar autologous chondrocyte implantation: mid-term results in a selected population. Knee Surg Sports Traumatol Arthrosc. 2009;17(1):2-10.

140. Fisher B, Nyland J, Brand E, Curtin B. Medial patellofemoral ligament reconstruction for recurrent patellar dislocation: a systematic review including rehabilitation and return-to-sports efficacy. Arthroscopy. 2010;26(10):1384-1394.

141. Smith TO, Donell ST, Chester R, Clark A, Stephenson R. What activities do patients with patellar instability perceive makes their patella unstable? Knee. 2011;18(5):333-339.

142. Atkin DM, Fithian DC, Marangi KS, Stone ML, Dobson BE, Mendelsohn C. Characteristics of patients with primary acute lateral patellar dislocation and their recovery within the first 6 months of injury. Am J Sports Med. 2000;28(4):472-479.

143. Ménétrey J, Putman S, Gard S. Return to sport after patellar dislocation or following surgery for patellofemoral instability. Knee Surg Sports Traumatol Arthrosc. 2014;22(10):23202326.

144. Kujala UM, Jaakkola LH, Koskinen SK, Taimela S, Hurme M, Nelimarkka O. Scoring of patellofemoral disorders. Arthroscopy. 1993;9(2):159-163.

145. Bennell K, Duncan M, Cowan S, McConnell J, Hodges P, Crossley $\mathrm{K}$. Effects of vastus medialis oblique retraining versus general quadriceps strengthening on vasti onset. Med Sci Sports Exerc. 2010;42(5):856-864. 